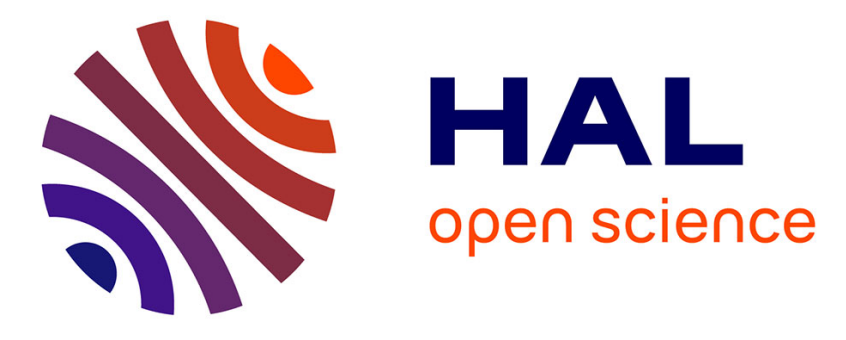

\title{
Complex diffusion behavior of oxygen in nanocrystalline BaTiO3 ceramics
}

\author{
Roger A. de Souza, Christophe Voisin, Henning Schraknepper, Markus \\ Teusner, Markus Kessel, Pascal Dufour, Christophe Tenailleau, Sophie \\ Guillemet-Fritsch
}

\section{To cite this version:}

Roger A. de Souza, Christophe Voisin, Henning Schraknepper, Markus Teusner, Markus Kessel, et al.. Complex diffusion behavior of oxygen in nanocrystalline BaTiO3 ceramics. Physical Chemistry Chemical Physics, 2013, vol. 16 ( ${ }^{\circ}$ 6), pp. 2568-2575. 10.1039/c3cp53979b . hal-01168945

\section{HAL Id: hal-01168945 \\ https://hal.science/hal-01168945}

Submitted on 26 Jun 2015

HAL is a multi-disciplinary open access archive for the deposit and dissemination of scientific research documents, whether they are published or not. The documents may come from teaching and research institutions in France or abroad, or from public or private research centers.
L'archive ouverte pluridisciplinaire HAL, est destinée au dépôt et à la diffusion de documents scientifiques de niveau recherche, publiés ou non, émanant des établissements d'enseignement et de recherche français ou étrangers, des laboratoires publics ou privés. 


\section{OATAO}

\section{Open Archive TOULOUSE Archive Ouverte (OATAO)}

OATAO is an open access repository that collects the work of Toulouse researchers and makes it freely available over the web where possible.

This is an author-deposited version published in : http://oatao.univ-toulouse.fr/ Eprints ID : 13965

To link to this article : DOI:10.1039/c3cp53979b

URL : http://dx.doi.org/10.1039/c3cp53979b

To cite this version : De Souza, Roger A. and Voisin, Christophe and Schraknepper, Henning and Teusner, Markus and Kessel, Markus and Dufour, Pascal and Tenailleau, Christophe and Guillemet-Fritsch, Sophie Complex diffusion behavior of oxygen in nanocrystalline BaTiO3 ceramics. (2013) Physical Chemistry Chemical Physics, vol. $16\left(\mathrm{n}^{\circ} 6\right)$. pp. 2568-2575. ISSN 1463-9076

Any correspondance concerning this service should be sent to the repository administrator: staff-oatao@listes-diff.inp-toulouse.fr 


\title{
Complex diffusion behavior of oxygen in nanocrystalline $\mathrm{BaTiO}_{3}$ ceramics $\dagger$
}

\author{
Roger A. De Souza, ${ }^{\text {a }}$ Christophe Voisin, ${ }^{\mathrm{b}}$ Henning Schraknepper, ${ }^{a}$ \\ Markus Teusner, ${ }^{a}$ Markus Kessel, ${ }^{a}$ Pascal Dufour, ${ }^{b}$ Christophe Tenailleau ${ }^{b}$ and \\ Sophie Guillemet-Fritsch ${ }^{b}$ \\ ${ }^{18} \mathrm{O} /{ }^{16} \mathrm{O}$ exchange annealing and subsequent Time-of-Flight Secondary lon Mass Spectrometry (ToF-SIMS) \\ analysis is used to investigate oxygen transport in dense, nanocrystalline (average grain size $d \approx 300 \mathrm{~nm}$ ) \\ ceramics of nominally un-doped $\mathrm{BaTiO}_{3}$. Isotope penetration profiles are obtained as a function of \\ temperature, $973<T / K<1173$, at an oxygen activity $\mathrm{aO}_{2}=0.20$ and as a function of oxygen activity, \\ $0.002<\mathrm{aO}_{2}<0.20$, at $T=1073 \mathrm{~K}$. All isotope profiles show the same unusual shape: a flattened profile \\ over the first $\sim 10^{2} \mathrm{~nm}$, followed by a short, conventional diffusion profile. We demonstrate that the entire \\ isotope profile can be described quantitatively by a numerical solution to the diffusion equation based on \\ an increase in the local oxygen diffusion coefficient close to the surface. This position-dependent increase \\ is attributed to additional oxygen vacancies that are generated by diffusion of chlorine impurities out of \\ the ceramics. The presence of chlorine derives from the chemical route necessary to produce nanometric \\ powders: it thus indicates a new manner in which nanocrystalline ceramics may differ from their \\ microcrystalline counterparts.
}

\section{Introduction}

By virtue of its large relative dielectric permittivity $\left(\varepsilon_{\mathrm{r}} \geq 1000\right)$, the perovskite oxide $\mathrm{BaTiO}_{3}$, barium titanate (BT), is the standard dielectric medium in current Multi-Layer Ceramic Capacitor (MLCC) technology. The continuing drive towards ever smaller MLCC dimensions has focused interest in BT on improving its $\varepsilon_{\mathrm{r}}$ at small grain sizes: it has been known for some time that BT's $\varepsilon_{\mathrm{r}}$ is a function of grain size $d$, the maximum value of $\varepsilon_{\mathrm{r}}=5000$ being found for $d \approx 1 \mu \mathrm{m}$, with a strong decrease for smaller grain sized ceramics. ${ }^{1,2}$ Surprisingly, $\varepsilon_{\mathrm{r}}$ in excess of $10^{5}$, so called colossal dielectric permittivity, has been observed recently for BT ceramics with $d<1 \mu \mathrm{m}$ that had been consolidated, not by conventional sintering, but by Spark Plasma Sintering (SPS). ${ }^{3}$ Although the origin of colossal dielectric permittivity in such nanocrystalline ceramics is unclear, ${ }^{3-13}$ the behaviour of oxygen vacancies and the high density of grain boundaries are thought to be critical. ${ }^{12,13}$

The aim of this study is to characterize the behaviour of oxygen vacancies in dense, nanocrystalline $\mathrm{BaTiO}_{3}$ (n-BT) ceramics, in order to elucidate their role in generating colossal dielectric

\footnotetext{
${ }^{a}$ Institute of Physical Chemistry, RWTH Aachen University and JARA-FIT, Landoltweg 2, 52056 Aachen, Germany. E-mail: desouza@pc.rwth-aachen.de

${ }^{b}$ Institut Carnot CIRIMAT, CNRS UMR 5085, Université Paul-Sabatier, 118 route de Narbonne, 31062 Toulouse Cedex 9, France

$\dagger$ Dedicated to Prof. Manfred Martin on the occasion of his 60th birthday.
}

permittivity. To this end, we conducted isotope exchange experiments with subsequent determination of isotope profiles within the solid by means of Time-of-Flight Secondary Ion Mass Spectrometry (ToF-SIMS). ${ }^{14,15}$ Such measurements provide an indirect, though powerful, method for studying the behaviour of oxygen vacancies in oxides. This stems from the simple relationship between the measured tracer diffusion coefficient $\left(D_{\mathrm{O}}^{*}\right)$ and the site fraction of vacancies $\left(n_{\mathrm{V}}\right)$

$$
D_{\mathrm{O}}^{*}=f^{*} D_{\mathrm{V}} n_{\mathrm{V}}
$$

where $D_{\mathrm{V}}$ is the vacancy diffusivity and $f^{*}$, the tracer correlation coefficient (a constant of order unity). Furthermore, the interaction between oxygen vacancies and interfaces (grain boundaries/ surfaces) can be probed. ${ }^{14}$

Oxygen diffusion in BT/MLCC has been investigated previously, ${ }^{16-21}$ but the emphasis in these studies has been on characterizing and understanding the post-sintering re-oxidation of BT, in order to improve the resistance degradation of MLCCs.

The electrical conductivity of nanocrystalline $\mathrm{BaTiO}_{3}{ }^{22,23}$ (and also of the analogous system of nanocrystalline $\mathrm{SrTiO}_{3}{ }^{24,25}$ ) has already been examined at elevated temperatures. In both cases (n-BT and n-ST) the experimental conductivity data can be accounted for quantitatively by the presence of space-charge layers at the grain boundaries. ${ }^{22-25}$ The formation of such layers can be explained in terms of oxygen vacancies residing preferentially within the grain-boundary cores, and thus being depleted from the adjacent bulk regions. ${ }^{26-28}$ This redistribution 


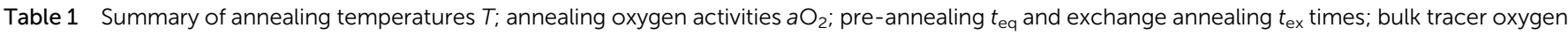

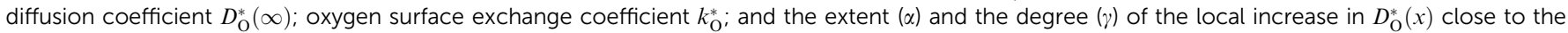
surface

\begin{tabular}{|c|c|c|c|c|c|c|c|}
\hline$T / \mathrm{K}$ & $a \mathrm{O}_{2}$ & $t_{\mathrm{eq}} / \mathrm{s}$ & $t_{\mathrm{ex}} / \mathrm{s}$ & $D_{\mathrm{O}}^{*}(\infty) / \mathrm{cm}^{2} \mathrm{~s}^{-1}$ & $k_{\mathrm{O}}^{*} / \mathrm{cm} \mathrm{s}^{-1}$ & $\alpha / \mathrm{nm}$ & $\gamma$ \\
\hline 900 & 0.2 & $6.45 \times 10^{4}$ & $1.04 \times 10^{3}$ & $1.4 \times 10^{-13}$ & $8.6 \times 10^{-8}$ & 120 & 8 \\
\hline 850 & 0.2 & $1.77 \times 10^{4}$ & $1.30 \times 10^{3}$ & $1.2 \times 10^{-13}$ & $3.8 \times 10^{-8}$ & 100 & 10 \\
\hline 800 & 0.2 & $1.55 \times 10^{4}$ & $1.81 \times 10^{3}$ & $5.0 \times 10^{-14}$ & $2.1 \times 10^{-8}$ & 90 & 10 \\
\hline 750 & 0.2 & $3.93 \times 10^{5}$ & $3.67 \times 10^{3}$ & $2.0 \times 10^{-14}$ & $4.2 \times 10^{-9}$ & 80 & 9 \\
\hline 700 & 0.2 & $1.13 \times 10^{5}$ & $9.05 \times 10^{3}$ & $9.5 \times 10^{-15}$ & $3.8 \times 10^{-9}$ & 70 & 6 \\
\hline 800 & 0.02 & $2.03 \times 10^{4}$ & $1.84 \times 10^{3}$ & $1.1 \times 10^{-13}$ & $5.7 \times 10^{-9}$ & 120 & 15 \\
\hline 800 & 0.002 & $2.86 \times 10^{4}$ & $1.88 \times 10^{3}$ & $1.2 \times 10^{-13}$ & $1.5 \times 10^{-9}$ & 75 & 10 \\
\hline
\end{tabular}

of oxygen vacancies sets up an electrical potential distribution that depletes electron holes within the space-charge zones, and it is this diminished concentration of electronic charge carriers that is observed in electrical conductivity measurements. The conductivity of nanocrystalline titanate perovskites is thus evidently governed by grain boundaries and, indirectly, by the behaviour of oxygen vacancies. Oxygen diffusion experiments, which specifically probe the behaviour of oxygen vacancies, could also provide further confirmation of the presence of space-charge layers at grain boundaries in n-BT ceramics.

\section{Experimental}

\subsection{Sample preparation and characterisation}

Nanometric powder of nominally undoped $\mathrm{BaTiO}_{3}$ was synthesized via an oxalate precipitation route, with stoichiometric amounts of $\mathrm{BaCl}_{2} \cdot 2 \mathrm{H}_{2} \mathrm{O}$ and $\mathrm{TiOCl}_{2}$, as described elsewhere. ${ }^{29}$ Most of the powder was calcined at $T=1123 \mathrm{~K}$ for $4 \mathrm{~h}$, a small part at $T=$ $1493 \mathrm{~K}$ for $48 \mathrm{~h}$, to give powders with two different starting particle sizes. Consolidation of the powders to dense ceramics was achieved by spark plasma sintering using a Dr Sinter 2080 apparatus (Sumimoto Coal Mining, SPS Syntx Inc., Japan): $c a .0 .9 \mathrm{~g}$ of powder was placed in a $8 \mathrm{~mm}$ diameter graphite die and then sintered at $T=1423 \mathrm{~K}$ with a dwell time of 3 minutes under an applied pressure of $50 \mathrm{MPa}$ and electric current of up to $350 \mathrm{~A}$. Due to the reducing atmosphere (vacuum) experienced by the samples during the SPS process, a post annealing treatment $(48 \mathrm{~h}$ at $1173 \mathrm{~K}$ in air) was performed in order to re-oxidize the ceramics. All samples exhibited a relative density higher than 98\%. FEG SEM observations revealed an average grain size of $c a .300 \mathrm{~nm}$ for the samples produced from the low-temperature calcined powder and ca. $1 \mu \mathrm{m}$ for ceramics from the high-temperature calcined powder. High-temperature, in situ X-ray diffraction analyses indicated that both samples are phase-pure, adopting cubic perovskite symmetry at the temperatures of the isotope anneals. After grinding and polishing, with a $1 \mu \mathrm{m}$ diamondpaste finish, a mean-square surface roughness of $c a .20 \mathrm{~nm}$ was achieved (according to interference microscopy measurements of an area of $738 \mu \mathrm{m} \times 480 \mu \mathrm{m})$.

XPS was carried out on the surface of ceramics using an Axis Ultra spectrometer (Kratos Analytical, Manchester, UK). ICP-OES (Jobin Yvon, JY 2000, Longjumeau, France) was performed on the powders to determine the $\mathrm{Ba}$ : Ti ratio and the impurity content.

\subsection{Exchange annealing and ToF-SIMS analysis}

The standard procedure for introducing an isotope penetration profile into a solid from a large volume of gas was used. ${ }^{14,15,30} \mathrm{~A}$ sample was first equilibrated for a time $t_{\mathrm{eq}}\left(t_{\mathrm{eq}}>8 t_{\mathrm{ex}}\right)$ at the temperature $T$ and oxygen activity $a \mathrm{O}_{2}$ of interest in oxygen of natural isotopic abundance, and then quenched to room temperature. It was subsequently given an anneal for a time $t_{\mathrm{ex}}$, in highly enriched ${ }^{18} \mathrm{O}_{2}$ gas (Isotec Inc., Miamisburg, USA) at the same temperature and oxygen partial pressure. A summary of the annealing times and temperatures is given in Table 1.

The oxygen isotope profiles in the $\mathrm{BaTiO}_{3}$ ceramics were measured by means of Time-of-Flight Secondary Ion Mass Spectrometry (ToF-SIMS) on a ToF-SIMS IV machine (IONTOF $\mathrm{GmbH}$, Münster, Germany). The measurements were performed with $25 \mathrm{keV} \mathrm{Ga}{ }^{+}$ions rastered over $80 \mu \mathrm{m} \times 80 \mu \mathrm{m}$ for ToF analysis (in burst mode, with a cycle time of $45 \mu \mathrm{s}$ ), $2 \mathrm{keV} \mathrm{Cs}^{+}$ ions rastered over $300 \mu \mathrm{m} \times 300 \mu \mathrm{m}$ for sputtering etching of the sample and $<20 \mathrm{eV}$ electrons for charge compensation. Negative secondary ions were detected. The pressure in the main chamber of the SIMS machine was below $10^{-9}$ mbar during analysis. A detailed description of the analysis procedures, in particular the method for correcting the ${ }^{16} \mathrm{O}^{-}$and ${ }^{18} \mathrm{O}^{-}$signals for the dead-time of the detector, is given elsewhere. ${ }^{31}$ Crater depths were determined post-analysis using an NT1100 interference microscope (Veeco Instruments Inc., NY, USA).

\section{Results}

We stress, first, that the n-BT ceramics used in this study exhibited $>98 \%$ theoretical density and adopted cubic symmetry at the temperatures of the isotope anneals.

Oxygen isotope profiles in a solid oxide are described by the appropriate solution to the diffusion equation

$$
\frac{\partial n^{*}}{\partial t}=\frac{\partial}{\partial x}\left(D_{\mathrm{O}}^{*} \frac{\partial n^{*}}{\partial x}\right)
$$

for the initial and boundary conditions defined by the experiment. For the case of isotope exchange between a large volume of gas and a semi-infinite medium characterized by a bulk tracer diffusion coefficient of oxygen, $D_{\mathrm{O}}^{*}$, and an oxygen surface exchange 
coefficient, $k_{\mathrm{O}}^{*}$, the solution is a modified complementary error function $^{32}$ (with $t_{\mathrm{ex}}$ being the duration of the isotope anneal)

$$
\begin{aligned}
n_{\mathrm{r}}^{*}= & \left.\operatorname{erfc} \frac{x}{2 \sqrt{D_{\mathrm{O}}^{*} t_{\mathrm{ex}}}}\right)-\exp \left(\frac{k_{\mathrm{O}}^{*} x}{D_{\mathrm{O}}^{*}}+\left[\frac{k_{\mathrm{O}}^{*}}{D_{\mathrm{O}}^{*}}\right]^{2} D_{\mathrm{O}}^{*} t_{\mathrm{ex}}\right) \\
& \left.\operatorname{erfc} \frac{x}{2 \sqrt{D_{\mathrm{O}}^{*} t_{\mathrm{ex}}}}+\frac{k_{\mathrm{O}}^{*}}{D_{\mathrm{O}}^{*}} \sqrt{D_{\mathrm{O}}^{*} t_{\mathrm{ex}}}\right) .
\end{aligned}
$$

The corrected isotope fraction, $n_{\mathrm{r}}^{*}$, is given by $n_{\mathrm{r}}^{*}=\left(n^{*}-n_{\mathrm{bg}}^{*}\right) /\left(n_{\mathrm{g}}^{*}-n_{\mathrm{bg}}^{*}\right)$, that is, it is the isotope fraction in the solid, $n^{*}$, corrected for the isotope fraction in the gas phase, $n_{\mathrm{g}}^{*}$, and for the background isotope fraction, $n_{\mathrm{bg}}^{*}$.

\subsection{Unusual form of the isotope diffusion profile}

In Fig. 1(a) we compare an isotope diffusion profile obtained by ToF-SIMS depth profiling of a dense n-BT ceramic with the best fit of eqn (3). Although the latter part of the profile is described
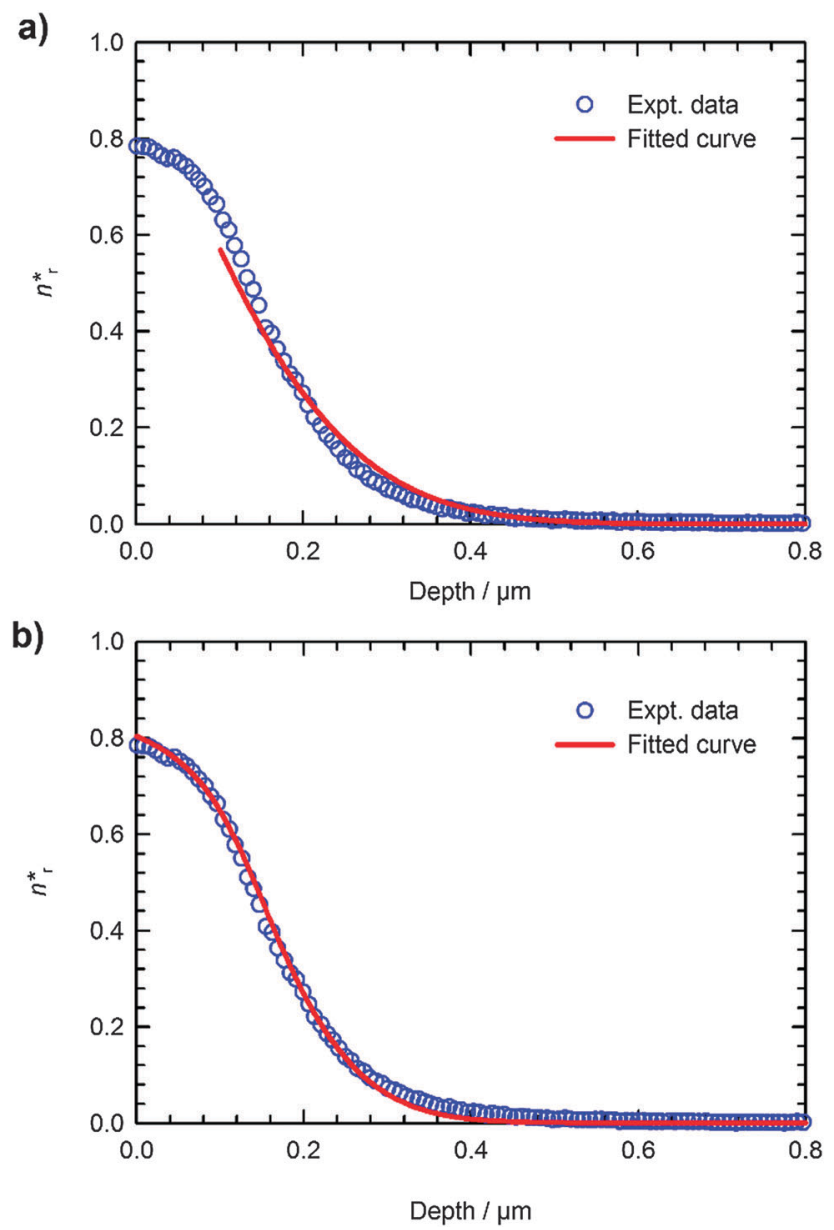

Fig. 1 An exemplary oxygen isotope diffusion profile obtained by ToFSIMS depth profiling of a nanocrystalline $\mathrm{BaTiO}_{3}$ ceramic (every 5th experimental data point plotted for clarity): (a) experimental profile compared with the fitted curve for a spatially invariant oxygen diffusion coefficient; (b) experimental profile compared with fitted curve for a spatially varying oxygen diffusion coefficient. Exchange anneal at $T=$ $1073 \mathrm{~K}$ and $\mathrm{aO}_{2}=0.2$ for $t_{\mathrm{ex}}=1.81 \times 10^{3} \mathrm{~s}$. well, there is a large deviation between the experimental data and the fitted curve over the first $100 \mathrm{~nm}$ or so. We discount SIMS artefacts, arising from preferential sputtering or rapidly changing concentrations, being responsible for this initial flattened region of the experimental diffusion profile, because we utilize (chemically identical) isotopes and quasi-simultaneous detection of both isotopes with ToF-SIMS. ${ }^{31,33}$ The deviation, therefore, is not from the analysis method, but from the sample. All isotope profiles measured in this study, for various temperatures and oxygen activities, exhibited this unusual shape.

The initial flattening of the diffusion profile suggests that the tracer diffusion coefficient is not constant over the first $\sim 10^{2} \mathrm{~nm}$. Specifically, it suggests an increase in tracer diffusion coefficient $D_{\mathrm{O}}^{*}(x)$, relative to $D_{\mathrm{O}}^{*}(\infty)$, the constant value in the bulk, far away from the surface. Indeed, assuming a spatial variation of the form

$$
D_{\mathrm{O}}^{*}(x)=D_{\mathrm{O}}^{*}(\infty)\left[1+\gamma \operatorname{erfc}\left(\frac{x}{\alpha}\right)\right],
$$

where $\gamma$ and $\alpha$ are variables describing the degree $(\gamma)$ and the extent $(\alpha)$ of the increase, we can describe the entire profile with a single solution of the diffusion equation, as shown in Fig. 1(b). As no analytical solution to eqn (2) is available for the case of $D_{\mathrm{O}}^{*}(x)$ given by eqn (4), numerical solutions were obtained with the finite element package Comsol (COMSOL AB, Stockholm, Sweden). The curve shown in Fig. 1(b) was found by visual comparison of the numerical solution with the experimental data. As will be shown below, all isotope profiles measured for these n-BT ceramics could be described in this manner, with $\gamma$ and $\alpha$ [and, of course, $D_{\mathrm{O}}^{*}(\infty)$ and $k_{\mathrm{O}}^{*}$ ] varying according to annealing times, temperatures and oxygen activities (see Table 1).

A small deviation between the theoretical curve and the experimental data is also evident in Fig. 1(b) at larger depths, $x>400 \mathrm{~nm}$. Such deviations are generally, ${ }^{34}$ but not necessarily, ${ }^{30}$ evidence of accelerated diffusion along grain boundaries. The origin of this deviation is unclear, as grain boundaries in BT have been demonstrated unambiguously to hinder oxygen transport. ${ }^{16,21}$ We leave this topic for future study.

\subsection{Effect of temperature, oxygen activity and grain size on the isotope profile}

Oxygen isotope profiles obtained as a function of temperature are shown, together with the fitted curves, in Fig. 2(a). The variation in $D_{\mathrm{O}}^{*}(x)$ required at each temperature to reproduce the theoretical profile is plotted in Fig. 2(b). Although the annealing times were not identical, the general trend is towards the extent of the increase in $D_{\mathrm{O}}^{*}(x)$ becoming more pronounced the higher the temperature: $\alpha$ increases monotonically from $70 \mathrm{~nm}$ at $T=973 \mathrm{~K}$ to $120 \mathrm{~nm}$ at $T=1173 \mathrm{~K}$. $\gamma$ is apparently independent of temperature, displaying values of the order of $\gamma \sim 10^{1}$.

Fig. 3(a) and (b) show the corresponding data for the variation of oxygen activity at constant temperature. As the annealing times are approximately constant, one can say that decreasing the oxygen activity decreases the amount of isotope 

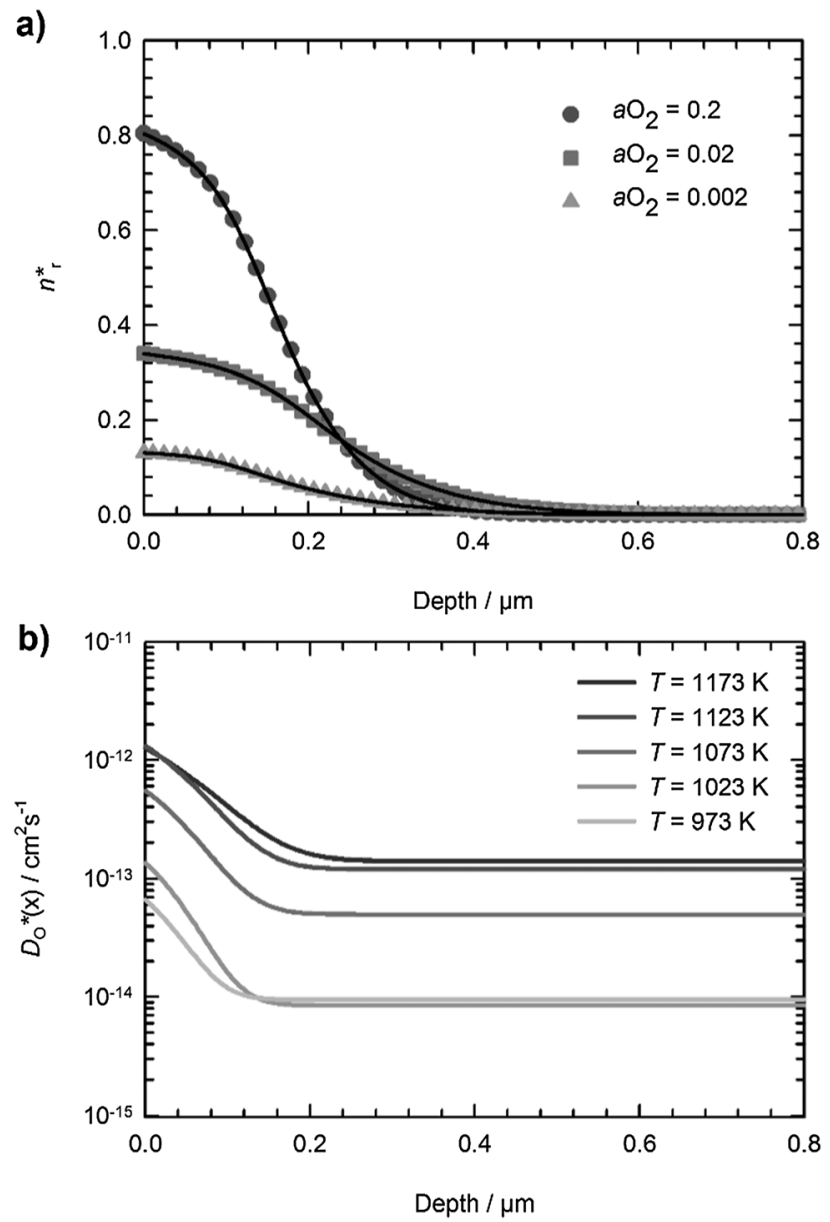

Fig. 2 (a) Experimental isotope diffusion profiles in nanocrystalline $\mathrm{BaTiO}_{3}$ ceramics (every 5 th experimental data point plotted for clarity) for various temperatures at $\mathrm{aO}_{2}=0.2$ together with fitted curves. (b) Spatial variation in the oxygen tracer diffusion coefficient employed to obtain fitted curves shown in (a).

incorporated into the material. This translates into $k_{\mathrm{O}}^{*}$ decreasing with decreasing oxygen activity, as $D_{\mathrm{O}}^{*}(\infty)$ [and $\alpha$ and $\gamma$ ] remain essentially constant.

In Fig. 4 we compare isotope diffusion profiles of two BT ceramics with different average grain sizes $(d=300 \mathrm{~nm}$ and $d=$ $1000 \mathrm{~nm}$ ), annealed for the same time at the same temperature and oxygen activity. The isotope diffusion front clearly penetrates further into the sample with the larger average grain size; the detailed analysis yields that $D_{\mathrm{O}}^{*}(\infty)$ is a factor of two higher. No significant changes are observed for $k_{\mathrm{O}}^{*}, \alpha$ or $\gamma$.

\section{Discussion}

\subsection{Origin of the unusual profile shape}

Isotope profiles of similar shape have been reported for donor-doped perovskite oxides, such as La-doped $\mathrm{SrTiO}_{3},{ }^{35}$ La-doped $\mathrm{BaTiO}_{3},{ }^{36}$ and $\mathrm{Nd}$-doped $\mathrm{Pb}(\mathrm{Zr}, \mathrm{Ti}) \mathrm{O}_{3}{ }^{37}$ In all three cases flattened isotope profiles were observed after isotope annealing under conditions, as it turned out, that did not correspond to thermodynamic equilibrium. a)


Fig. 3 (a) Experimental isotope diffusion profiles in nanocrystalline $\mathrm{BaTiO}_{3}$ ceramics (every 5th experimental data point plotted for clarity) for three oxygen activities at $T=1073 \mathrm{~K}$ together with fitted curves. (b) Spatial variation in the oxygen tracer diffusion coefficient employed to obtain fitted curves shown in (a).

Indeed, the samples were undergoing a slow transition under charge neutrality conditions from cation donors being compensated by electrons to cation donors being compensated by cation vacancies. The introduction of cation vacancies into the lattice from the surface causes the oxygen vacancy concentration to increase locally. ${ }^{35-39}$ In our case, n-BT ceramics, though nominally undoped, were found by chemical analysis to contain calcium and iron, common acceptor-like impurities in alkaline earth titanates, ${ }^{40-44}$ at a level of $\left[\right.$ Acc' $\left.^{\prime}\right] \sim 10^{25} \mathrm{~m}^{-3}$, but no donor-like impurities, such as La or Nb. Furthermore, minor deviations from unity in the Ba:Ti ratio, which are unavoidable, lead to cation vacancies on one or other of the cation sublattices, and these defects, too, act as acceptors. Although chemical analysis yielded $\mathrm{Ba}: \mathrm{Ti}=1.00 \pm 0.01$, a deviation of 0.01 is sufficient to yield an upper limit for the acceptor concentration of the order of $\left[\mathrm{Acc}^{\prime}\right] \sim 10^{26} \mathrm{~m}^{-3}$. On this basis, we conclude that our samples are acceptor-doped, and hence the explanation in the literature, ${ }^{35-39}$ which requires the material to be donor doped, cannot apply here; below we propose an alternative explanation. 

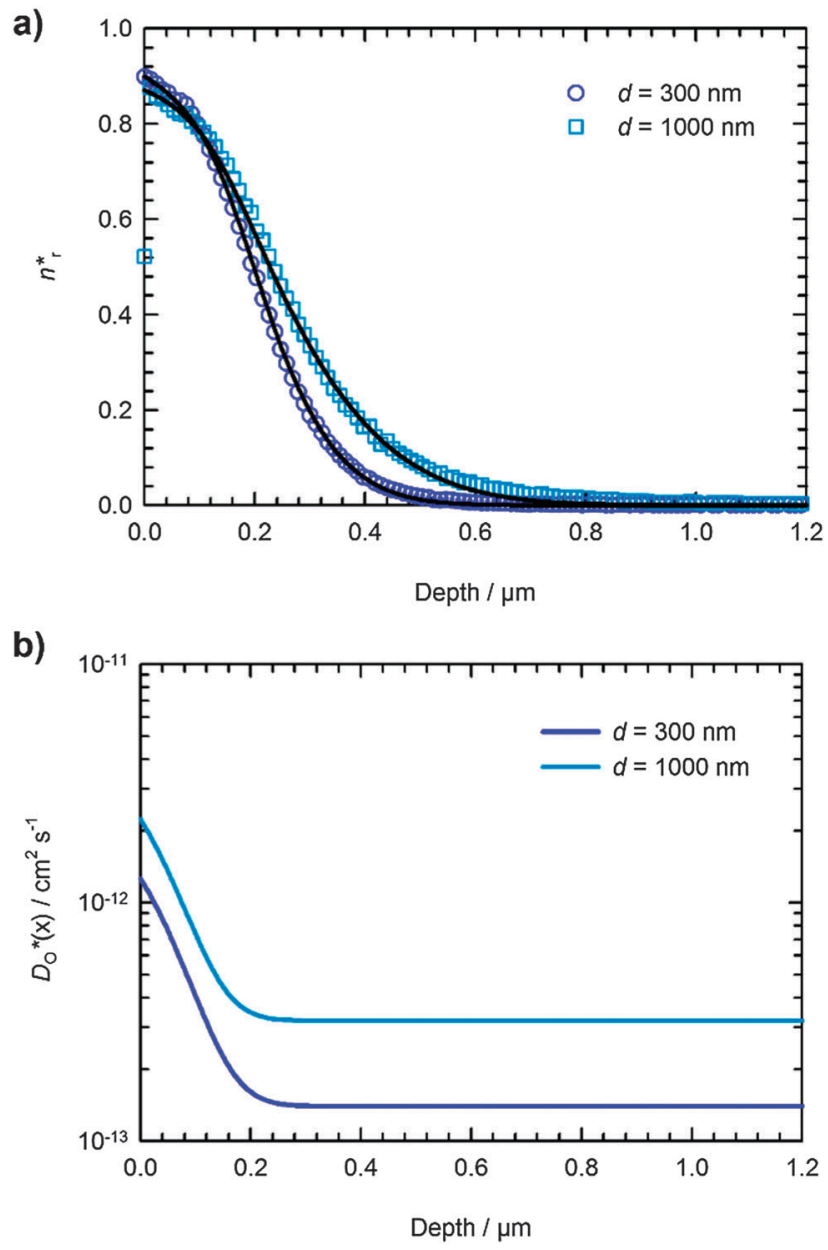

Fig. 4 Effect of grain size on experimental isotope profiles in nanocrystalline $\mathrm{BaTiO}_{3}$ ceramics (every 10th experimental data point plotted for clarity). Both samples were isotope exchanged at $T=1073 \mathrm{~K}$ and $\mathrm{aO}_{2}=0.2$ for $t_{\mathrm{ex}}=1.04 \times$ $10^{4} \mathrm{~s}$. (a) Experimental isotope profiles. (b) Spatial variation in the oxygen tracer diffusion coefficient employed to obtain fitted curves shown in (a).

In view of $D_{\mathrm{O}}^{*}(x)$ evidently following an erfc form and the annealing times and temperatures evidently being relevant variables, we deduce that a diffusion process is responsible for the increased local diffusivity. But which species are diffusing? Significant cation mobility at these temperatures seems to be unlikely. ${ }^{45}$ Rather, inspection of the ToF-SIMS mass spectra indicates unambiguously the presence of a small amount of chlorine (both stable isotopes were detected, ${ }^{35} \mathrm{Cl}$ and ${ }^{37} \mathrm{Cl}$, in the correct natural abundance ratio of $c a .3: 1$ ) in all n-BT ceramics. In Fig. 5 we plot, exemplarily for the data shown in Fig. 1, the normalized chlorine signal, $I_{\mathrm{Cl}}^{\mathrm{norm}}=I_{35_{\mathrm{Cl}}} /\left(I_{16_{\mathrm{O}}}+I_{18_{\mathrm{O}}}\right)$, extracted from the original ToF-SIMS depth profile, together with the spatial variation in $D_{\mathrm{O}}^{*}(x)$ used to describe the isotope penetration profile. $D_{\mathrm{O}}^{*}(x)$ is seen to rise over exactly the same distance as $I_{\mathrm{Cl}}^{\text {norm }}$ falls. This suggests that the charge neutrality condition is

$$
\left[\mathrm{Acc}^{\prime}\right]=\left[\mathrm{Cl}_{\mathrm{O}}^{\bullet}\right]+2\left[\mathrm{~V}_{\mathrm{O}}^{\bullet \bullet}\right]
$$

The loss of $\mathrm{Cl}^{-}$from the lattice thus causes an increase in oxygen vacancy concentration; and this increase in vacancy

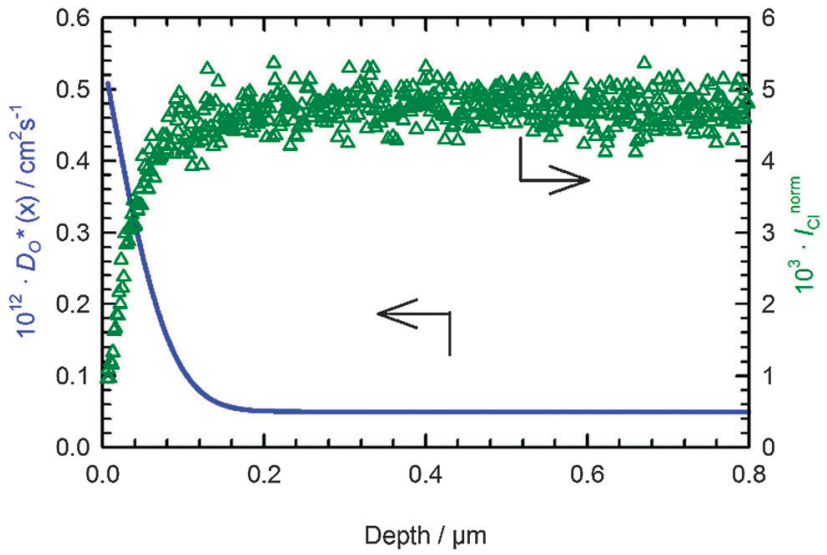

Fig. 5 Normalized $\mathrm{Cl}$ intensity profile, $I_{\mathrm{Cl}}^{\text {norm }}$, and spatial variation in local tracer diffusion coefficient, $D_{\mathrm{O}}^{*}(x)$, for the exemplary isotope profile shown in Fig. 1.

concentration results directly in an increase in the local tracer diffusion coefficient [see eqn (1), $D_{\mathrm{O}}^{*}(x) \propto n_{\mathrm{V}}(x)$ ]. The unusual profile originates, therefore, from donor-species, $\mathrm{Cl}_{\mathrm{O}}^{\circ}$, diffusing out of acceptor-doped BT.

Presumably chlorine diffuses out of the n-BT ceramics when the material is subjected to a high-temperature anneal in an atmosphere of low chlorine activity, i.e., in the gaseous oxygen of the equilibration and exchange anneals. Its concentration profile is expected, therefore, to follow an error function (erf) form, and it does. Consequently, the profiles of $n_{\mathrm{V}}(x)$, and hence of $D_{\mathrm{O}}^{*}(x)$, should take an erfc form: that this is precisely the empirical ansatz of eqn (4) provides further support for our hypothesis. Accordingly, the variable $\alpha$ refers to the characteristic diffusion length of chlorine during the treatment in oxygen,

$$
\alpha=2 \sqrt{D_{\mathrm{Cl}}^{\delta}\left(t_{\mathrm{eq}}+t_{\mathrm{ex}}\right)},
$$

with the corresponding transport parameter being the chemical diffusion coefficient of $\mathrm{Cl}$ in $\mathrm{n}-\mathrm{BT}, D_{\mathrm{Cl}}^{\delta}$.

$k_{\mathrm{Cl}}^{\delta}$ and $D_{\mathrm{Cl}}^{\delta}$ can of course be obtained by fitting eqn (3) to the $I_{\mathrm{Cl}}^{\text {norm }}$ profile, corrected for the initial and background intensities. As the $\mathrm{Cl}$ intensity profile is noisier, however, than the oxygen isotope profile (compare Fig. 5 with Fig. 1), the transport parameters obtained in this manner have larger errors. In other words, the indirect method of determining $D_{\mathrm{Cl}}^{\delta}$, via the oxygen isotope profile, provides superior results to the direct fitting of the $\mathrm{Cl}$ intensity profile. It should also be noted, as $k_{\mathrm{Cl}}^{\delta} / D_{\mathrm{Cl}}^{\delta}>10^{5} \mathrm{~cm}^{-1}$, that $\mathrm{Cl}$ transport is limited by bulk diffusion and not surface kinetics and hence the $\mathrm{Cl}$ profile is adequately described by a simple, as opposed to a modified, erf form; and also, that the values of $k_{\mathrm{Cl}}^{\delta}$ obtained thus represent lower limits.

Incidentally, the presence of a surface space-charge layer as the cause of the spatially variant diffusion coefficient can be excluded for two reasons. First, the concentration profiles obtained experimentally for $\mathrm{Cl}_{\mathrm{O}}^{\bullet}$ and $\mathrm{V}_{\mathrm{O}}^{\bullet}$ are complementary (see Fig. 5): $\mathrm{Cl}_{\mathrm{O}}^{\bullet}$ is depleted; $\mathrm{V}_{\mathrm{O}}^{\bullet \bullet}$ is accumulated. If a space-charge layer was present, both species, on account of their positive charge, would have to display the same trend (both enhanced or 
both depleted). Second, surface space-charge layers in acceptordoped titanate perovskites $\left[\mathrm{BaTiO}_{3},{ }^{46} \mathrm{SrTiO}_{3}{ }^{32,33,47}\right.$ and $\left.\mathrm{Pb}(\mathrm{Zr}, \mathrm{Ti}) \mathrm{O}_{3}{ }^{48}\right]$ are characterised by depletion of $\mathrm{V}_{\mathrm{O}}^{*}$ close to the surface; the evidence gathered in this study indicates accumulation of oxygen vacancies close to the surface (see Fig. 2 and 3).

\subsection{Chlorine in $\mathrm{BaTiO}_{3}$ : origin and concentration}

The obvious source of $\mathrm{Cl}$ is the preparation route: the BT powders were prepared from chlorides of barium and titanium. Avoiding the presence of chemical components, such as chlorine, in the final powders is difficult in this case: in order to prepare dense ceramics with an average grain size in the nanometer range, one has to start with a powder with a correspondingly small particle size. This is best achieved (i) via a precipitation route (rather than via a solidstate reaction route) and (ii) by eschewing calcination at high temperatures that would lead to unwanted grain growth, but would drive most, if not all, of the chlorine out. In this sense, other starting reagents, such as nitrates or alkoxides, are preferable to chlorides, as they do not provide an unwanted anion that is easily incorporated into the perovskite lattice.

To determine from the SIMS data the exact amount of $\mathrm{Cl}$ in the n-BT ceramics, that is, to convert the measured $\mathrm{Cl}$ secondary ion intensity into a concentration, one requires a suitable SIMS standard, namely a known small amount of $\mathrm{Cl}$ in a $\mathrm{BaTiO}_{3}$ matrix. Such a standard was, unfortunately, not available. We pursued therefore direct determination of the $\mathrm{Cl}$ concentration by means of X-ray Photoelectron Spectroscopy (XPS), but failed to find any Cl, down to a detection limit of $0.1 \%$. This is consistent with the SIMS analysis, in the sense that SIMS is far more sensitive (i.e. has far lower detection limits) than XPS. It is also consistent with eqn (5), since both $\left[\mathrm{Acc}^{\prime}\right]$ and $\left[\mathrm{Cl}_{\mathrm{O}}^{\circ}\right]$ are at most $\sim 10^{26} \mathrm{~m}^{-3}$ (and, in all likelihood, much lower), and eqn (5) requires $\left[\mathrm{Cl}_{\mathrm{O}}^{*}\right] \leq\left[\mathrm{Acc}^{\prime}\right]$.

Although we have no exact numbers for the concentration of the dominant defects (acceptors, chlorine donors, and oxygen vacancies), we can place limits on their relative amounts. Since the $\mathrm{Cl}$ intensity at the surface decreases by a factor of $4-6$, and the increase in vacancy concentration $(\gamma)$ is of the order of $10^{1}$, it follows that $\left[\mathrm{Cl}_{\mathrm{O}}^{*}\right]$ and $\left[\mathrm{V}_{\mathrm{O}}^{*}\right]$ are of a similar order of magnitude. If $\left[\mathrm{Acc}^{\prime}\right] \approx\left[\mathrm{Cl}_{\mathrm{O}}^{*}\right] \gg 2\left[\mathrm{~V}_{\mathrm{O}}^{\bullet \bullet}, \gamma\right.$ would be much larger than $10^{1}$. If, on the other hand, $\left[\mathrm{Acc}^{\prime}\right] \approx 2\left[\mathrm{~V}_{\mathrm{O}}^{*}\right] \gg\left[\mathrm{Cl}_{\mathrm{O}}^{*}\right]$, the effect of $\mathrm{Cl}$ out-diffusion would not be apparent in $D_{\mathrm{O}}^{*}(x)$. In this sense ( $c f$. donor-doped perovskite oxides ${ }^{35-39}$ ), the n-BT samples are also not in equilibrium during the isotope anneals, but they do not undergo a marked transition under charge neutrality conditions.

\subsection{Diffusion coefficients}

Fig. 6 is an Arrhenius plot of $D_{\mathrm{O}}^{*}(\infty)$ and $D_{\mathrm{Cl}}^{\delta}$ obtained for the n-BT ceramics, together with $D_{\mathrm{O}}^{*}(\infty)$ data obtained for single crystal $\mathrm{BaTiO}_{3}$ (sc-BT). ${ }^{46}$ We consider, first, the two sets of oxygen tracer diffusion coefficients.

Values of $D_{\mathrm{O}}^{*}(\infty)$ for n-BT are seen to be a factor of $c a .10^{3}$ lower than those for sc-BT. This difference may be due [see eqn (1)] to $D_{\mathrm{V}}$ and/or to $n_{\mathrm{V}}$ being lower in the nanocrystalline system. As the migration of oxygen vacancies takes place, in

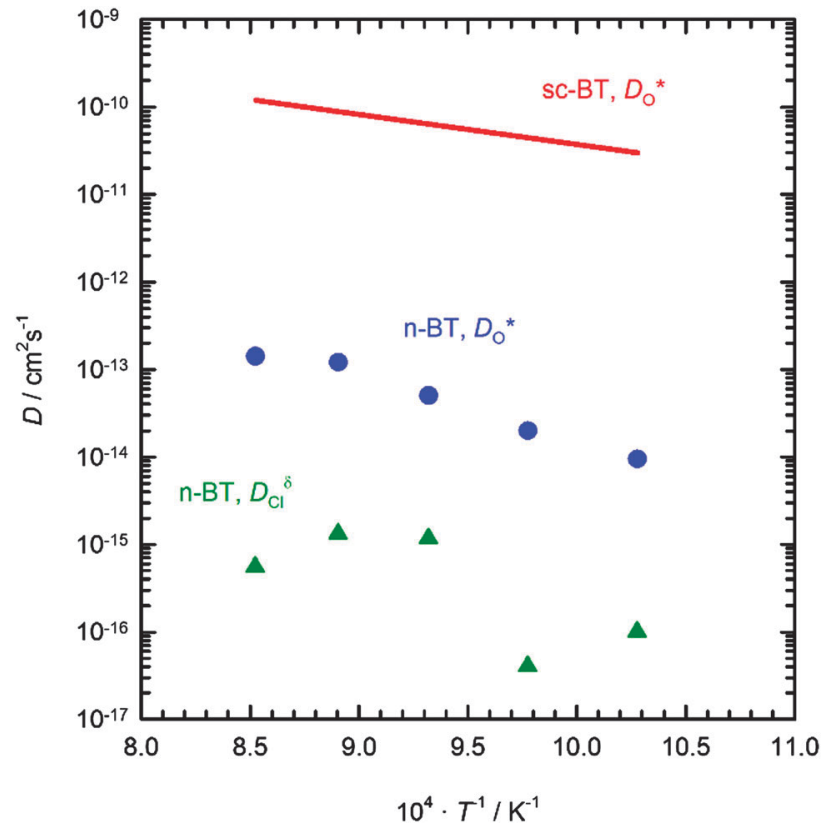

Fig. 6 Tracer diffusion coefficient of oxygen and chemical diffusion coefficient of chlorine in nanocrystalline $\mathrm{BaTiO}_{3}$ ( $n-\mathrm{BT}$ ) as a function of inverse temperature. Also shown for comparison is the oxygen diffusion coefficient in single crystal $\mathrm{BaTiO}_{3}$ (sc-BT). ${ }^{46}$

both n-BT and sc-BT, in a weakly doped, cubic $\mathrm{BaTiO}_{3}$ matrix, it seems to be reasonable to discount a significant variation in $D_{\mathrm{v}}$ : it is $n_{\mathrm{V}}$, then, that differs between the two systems. Conceivably, a difference in $n_{\mathrm{V}}$ may arise from the dissimilar microstructures (single crystal $v s$. high density of grain boundaries), from the dissimilar compositions (specifically, the type and amount of aliovalent impurities), or from some combination thereof. According to the arguments presented in the previous sections, however, the effective concentration of acceptors in n-BT $\left(=\left[\mathrm{Acc}^{\prime}\right]-\left[\mathrm{Cl}_{\mathrm{O}}^{\circ}\right]\right)$, though not known, is certainly not $10^{3}$ lower than that in sc-BT $\left(\left[\mathrm{Acc}^{\prime}\right] \approx 4 \times 10^{24} \mathrm{~m}^{-3}\right) \cdot{ }^{46}$ Consequently we conclude that grain boundaries, or to be more precise, space-charge layers at grain boundaries, are responsible for the severe decrease in oxygen-vacancy concentration in the n-BT ceramics. Charge-carrier concentrations in spacecharge layers can be easily enhanced or depressed by orders of magnitude, relative to their bulk values. ${ }^{26-28,52}$ The high activation enthalpy of oxygen diffusion obtained for n-BT, $\Delta H\left(D_{\mathrm{O}}^{*}\right)=(1.42 \pm 0.13) \mathrm{eV}$, is a convolution of the vacancy migration enthalpy and the space-charge potential. [The value for sc-BT ${ }^{46}$ is $\left.\Delta H\left(D_{\mathrm{O}}^{*}\right)=(0.68 \pm 0.06) \mathrm{eV}\right]$.

We refrain from further analysis, partly because defect concentrations are not known with any certainty, but primarily because the diffusion front of oxygen in the n-BT samples takes in but a few grains $\left(d \sim \sqrt{D_{\mathrm{O}}^{*}(\infty) t_{\mathrm{ex}}}\right)$, rather than many grains $\left(d \ll \sqrt{D_{\mathrm{O}}^{*}(\infty) t_{\mathrm{ex}}}\right)$ or a fraction of one grain $\left(d \gg \sqrt{D_{\mathrm{O}}^{*}(\infty) t_{\mathrm{ex}}}\right)$. The diffusion kinetics thus fall between regimes (Harrison type A and Harrison type B) ${ }^{53}$ for which analytical equations are available. ${ }^{34}$ This constitutes another complexity in the diffusion behavior of oxygen in these n-BT samples. 
Nevertheless, it is clear that the increase in oxygen diffusion coefficient on going from the n-BT ceramic with $d=300 \mathrm{~nm}$ to that with $d=1000 \mathrm{~nm}$ could, similarly, be microstructural (fewer grain boundaries) or compositional (less chlorine) in origin. Indeed SIMS analysis indicated a lower level of chlorine in the sample with the larger grain size: this is to be expected in view of the starting powder being calcined at a much higher temperature for a longer time. In previous cases, ${ }^{22-25}$ differences in the transport behavior of nano- and microcrystalline ceramics were ascribed to the density of grain boundaries. The possible presence of volatile anion substituents was ignored.

The appearance of colossal dielectric permittivity in n-BT ceramics produced by SPS has various possible origins. ${ }^{12,13,49-51}$ In these particular samples it has been suggested ${ }^{12,13}$ to be linked to the behaviour of oxygen vacancies and grain boundaries. Oxygen vacancies certainly show rather complex behaviour in n-BT, but partly because of the presence of chlorine. In how far $\mathrm{Cl}_{\mathrm{O}}^{\bullet}$ (by influencing $\mathrm{V}_{\mathrm{O}}^{\bullet \bullet}$ ) is indirectly responsible for colossal dielectric permittivity remains to be seen.

We turn now to the $D_{\mathrm{Cl}}^{\delta}$ data. These show considerable scatter, most likely because the surface roughness ( $c a .20 \mathrm{~nm}$ ) is an appreciable fraction of the characteristic diffusion length of $\mathrm{Cl}(\alpha=70-130 \mathrm{~nm})$. This is reflected in the large error determined for the activation enthalpy of Cl diffusion, $\Delta H\left(D_{\mathrm{O}}^{\delta}\right)=$ $(1.55 \pm 0.85) \mathrm{eV}$. Nevertheless, $D_{\mathrm{Cl}}^{\delta}$ is consistently lower than $D_{\mathrm{O}}^{*}(\infty)$, by $c a$. two orders of magnitude, at all temperatures examined.

Chemical diffusion of chlorine out of $\mathrm{BaTiO}_{3}$ refers to the removal of $\mathrm{Cl}$ as a neutral chemical component from the lattice. It therefore requires, because $\mathrm{Cl}_{\mathrm{O}}^{\circ}$ is charged, the coupled transport of another charged defect (ambipolar diffusion). This is most probably an electron hole, since acceptor-doped BT is a $p$-type conductor at the temperatures and oxygen activities of the isotope anneals. ${ }^{40-44}$ Consequently, as $\sigma_{p} \gg \sigma_{\mathrm{O}} \gg \sigma_{\mathrm{Cl}}$, one may assume that the chemical diffusion of $\mathrm{Cl}$ is governed by the diffusion of $\mathrm{Cl}_{\mathrm{O}}^{\circ}$.

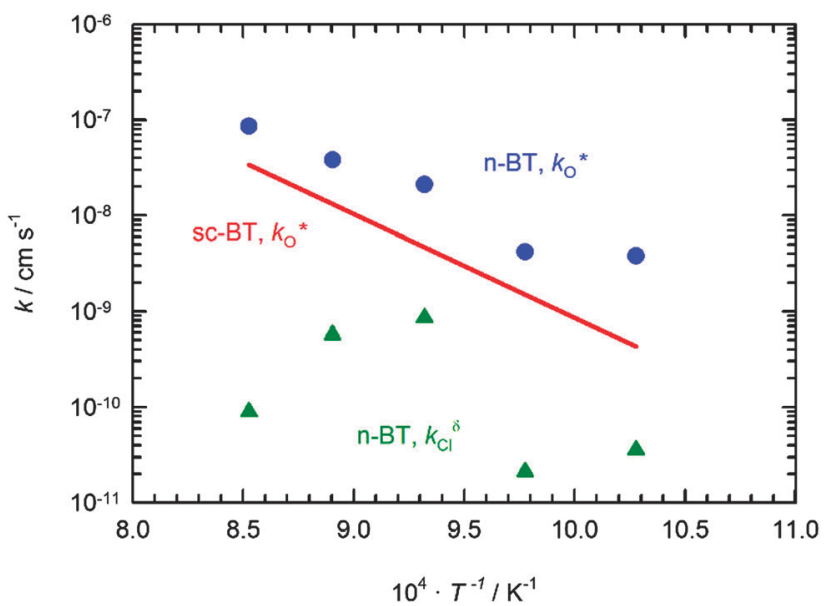

Fig. 7 Surface exchange coefficients of oxygen and of chlorine in $\mathrm{BaTiO}_{3}$ as a function of inverse temperature. Also shown for comparison is the oxygen surface exchange coefficient of single crystal $\mathrm{BaTiO}_{3}{ }^{46}$
Although the large error in the activation enthalpy prevents a more detailed analysis, we suggest that the migration enthalpy of $\mathrm{Cl}^{-}$is likely to be higher than that of $\mathrm{O}^{2-}$. The former has a much larger ionic radius in six-fold co-ordination $\left(r_{\mathrm{CI}}^{\mathrm{VI}}=1.81 \AA\right)$ than the latter $\left(r_{\mathrm{O}^{2-}}^{\mathrm{VI}}=1.40 \AA\right) .{ }^{54}$ Anion migration in $\mathrm{ABO}_{3}$ perovskite-type oxides occurs by the migrating ion jumping along $\langle 110\rangle$ directions, through a narrow aperture defined by two A cations and one B cation: ${ }^{55-58}$ the larger the migrating ion, the more the lattice has to be perturbed by the migrating ion, and consequently the higher the migration barrier.

Lastly we note that the surface reaction coefficients for $\mathrm{Cl}$ loss, $k_{\mathrm{Cl}}^{\delta}$, are intriguingly close to those for oxygen surface exchange in n-BT and sc-BT (see Fig. 7), especially if one bears in mind that the $k_{\mathrm{Cl}}^{\delta}$ data represent lower limits. Investigating the kinetics of anion substituent exchange in oxides may provide a new avenue for studying the oxygen reduction reaction.

\section{Conclusions}

Through our investigations on dense, nanocrystalline ceramics of $\mathrm{BaTiO}_{3}$ we conclude that in our samples:

(1) Oxygen diffusion is complex, with the complexity arising not only from the microstructure (grain boundaries; diffusion length relative to grain size) but also from the composition (anion impurity: chlorine).

(2) The presence of $\mathrm{Cl}$, at a very low level, comes from the preparation procedure that was used to produce the nanometric starting powder.

(3) The diffusion of chlorine in $\mathrm{BaTiO}_{3}$ occurs far more slowly than the diffusion of oxygen.

(4) The presence and diffusion kinetics of $\mathrm{Cl}$ open an additional avenue by which the behaviour of point defects in nanocrystalline ceramics may differ from that in their microcrystalline counterparts.

\section{Acknowledgements}

The authors thank Etienne Laborde for the XPS analyses. This study was supported by funding from DGAC (ISS2 project) and the University of Toulouse (ATUPS grant).

\section{Notes and references}

1 K. Kinoshita and A. Yamaji, J. Appl. Phys., 1976, 47, 371.

2 G. Arlt and D. Hennings, and G. Dewith, J. Appl. Phys., 1985, 58, 1619.

3 S. Guillemet-Fritsch, Z. Valdez-Nava, C. Tenailleau, T. Lebey, B. Durand and J.-Y. Chane-Ching, Adv. Mater., 2008, 20, 551.

4 T. Takeuchi, M. Tabuchi and H. Kageyama, J. Am. Ceram. Soc., 1999, 82, 939.

5 T. Takeuchi E. Betourne, M. Tabuchi, H. Kageyama, Y. Kobayashi, A. Coats, F. Morrison, D. C. Sinclair and A. R. West, J. Mater. Sci., 1999, 34, 917. 
6 W. Luan, L. Gao, H. Kawaoka, T. Sekino and K. Niihara, Ceram. Int., 2004, 30, 405.

7 B. Li, X. Wang, L. Li, H. Zhou, X. Liu, X. Han, Y. Zhang, X. Qi and X. Deng, Mater. Chem. Phys., 2004, 83, 23.

8 M. T. Buscaglia, V. Buscaglia, M. Viviani, J. Petzelt, M. Savinov, L. Mitoseriu, A. Testino, P. Nanni, C. Harnagea, Z. Zhao and M. Nygren, Nanotechnology, 2004, 15, 1113.

9 Z. Zhao, V. Buscaglia, M. Viviani, M. T. Buscaglia, L. Mitoseriu, A. Testino, M. Nygren, M. Johnsson and P. Nanni, Phys. Rev. B: Condens. Matter Mater. Phys., 2004, 70, 024107.

10 J. Liu, Z. Shen, M. Nygren, B. Su and T. W. Button, J. Am. Ceram. Soc., 2006, 89, 2689.

11 S. Yoon, J. Dornseiffer, Y. Xiong, D. Grüner, Z. Shen, S. Iwaya, C. Pithan and R. Waser, J. Eur. Ceram. Soc., 2011, 31, 1723 .

12 H. Han, C. Voisin, S. Guillemet-Fritsch, P. Dufour, C. Tenailleau, C. Turner and J. C. Nino, J. Appl. Phys., 2013, 113, 024102.

13 C. Voisin, S. Guillemet-Fritsch, P. Dufour, C. Tenailleau, H. Han and J. C. Nino, Int. J. Appl. Ceram. Technol., 2013, 10, E122, DOI: 10.1111/ijac.12058.

14 R. A. De Souza and M. Martin, Mater. Res. Bull., 2009, 34, 907.

15 J. A. Kilner, S. J. Skinner and H. H. Brongersma, J. Solid State Electrochem., 2011, 15, 861.

16 C. Schaffrin, Phys. Status Solidi A, 1976, 35, 79.

17 J. Itoh, D.-C. Park, N. Ohashi, I. Sakaguchi, I. Yashima, H. Haneda and J. Tanaka, J. Ceram. Soc. Jpn., 2002, 110, 495.

18 M. R. Opitz, K. Albertsen, J. J. Beeson, D. F. Henning, J. L. Routbort and C. A. Randall, J. Am. Ceram. Soc., 2003, 86, 1879.

19 M. Kessel, R. A. De Souza, H.-I. Yoo and M. Martin, Appl. Phys. Lett., 2010, 97, 021910.

20 K. Kaneda, S. Lee, N. J. Donnelly, W. Qu, C. A. Randall and Y. Mizuno, J. Am. Ceram. Soc., 2011, 94, 3934.

21 K. Watanabe, I. Sakaguchi, S. Hishita, H. Haneda and N. Ohashi, Key Eng. Mater., 2013, 566, 262.

22 X. Guo, C. Pithan, C. Ohly, C.-L. Jia, J. Dornseiffer, F.-H. Haegel and R. Waser, Appl. Phys. Lett., 2005, 86, 082110.

23 X. Guo, Acta Mater., 2013, 61, 1748.

24 P. Balaya, J. Jamnik, J. Fleig and J. Maier, Appl. Phys. Lett., 2006, 88, 062109.

25 P. Lupetin, G. Gregori and J. Maier, Angew. Chem., 2010, 122, 10321.

26 R. Waser and R. Hagenbeck, Acta Mater., 2000, 48, 797.

27 P. C. McIntyre, J. Am. Ceram. Soc., 2000, 83, 1129.

28 R. A. De Souza, Phys. Chem. Chem. Phys., 2009, 11, 9939.

29 Z. Valdez-Nava, S. Guillemet-Fritsch, C. Tenailleau, T. Lebey, B. Durand and J. Y. Chane-Ching, J. Electroceram., 2009, 22, 238.

30 R. A. De Souza and R. J. Chater, Solid State Ionics, 2005, 176, 1915.
31 R. A. De Souza, J. Zehnpfenning, M. Martin and J. Maier, Solid State Ionics, 2005, 176, 1465.

32 J. Crank, The Mathematics of Diffusion, Oxford Science Publications, Oxford, 2nd edn, 1975, p. 36.

33 R. A. De Souza and M. Martin, Phys. Chem. Chem. Phys., 2008, 10, 2356.

34 H. Mehrer, Diffusion in Solids Fundamentals, Methods, Materials, Diffusion-Controlled Processes, Springer-Verlag, Berlin Heidelberg, 2007, ch. 32 \& 34.

35 R. Meyer, R. Waser, J. Helmhold and G. Borchardt, Phys. Rev. Lett., 2003, 90, 105901.

36 T. Frömling, J. Hou, W. Preis, W. Sitte, H. Hutter and J. Fleig, J. Appl. Phys., 2011, 110, 043531.

37 T. Frömling, H. Hutter and J. Fleig, J. Am. Ceram. Soc., 2012, 95, 1692.

38 H.-I. Yoo and C.-E. Lee, J. Am. Ceram. Soc., 2005, 88, 617. 39 W. Preis and W. Sitte, Solid State Ionics, 2006, 177, 2549.

40 S. A. Long and R. N. Blumenthal, J. Am. Ceram. Soc., 1971, 54, 577.

41 N.-H. Chan and D. M. Smyth, J. Electrochem. Soc., 1976, 123, 158.

42 R. Wernicke, Philips Res. Rep., 1976, 31, 52643.

43 N.-H. Chan, R. K. Sharma and D. M. Smyth, J. Am. Ceram. Soc., 1981, 64, 556.

44 (a) H.-I. Yoo, C.-R. Song and D.-K. Lee, J. Electroceram., 2002, 8, 5; (b) D. M. Smyth, J. Electroceram., 2003, 11, 89.

45 S. Koerfer, R. A. De Souza, H.-I. Yoo and M. Martin, Solid State Sci., 2008, 10, 725.

46 M. Kessel, R. A. De Souza and M. Martin, in preparation.

47 R. A. De Souza, V. Metlenko, D. Park and T. Weirich, Phys. Rev. B: Condens. Matter Mater. Phys., 2012, 85, 174109.

48 R.-V. Wang and P. C. McIntyre, J. Appl. Phys., 2005, 97, 023508.

49 F. D. Morrison, D. C. Sinclair, J. M. S. Skakle and A. R. West, J. Am. Ceram. Soc., 1998, 81, 1957.

50 A. R. West, T. B. Adams, F. D. Morrison and D. C. Sinclair, J. Eur. Ceram. Soc., 2004, 24, 1439.

51 P. Lunkenheimer, V. Bobnar, A. V. Pronin, A. I. Ritus, A. A. Volkov and A. Loidl, Phys. Rev. B: Condens. Matter Mater. Phys., 2002, 66, 052105.

52 J. Maier, Physical Chemistry of Ionic Materials, John Wiley and Sons, Chichester, UK, 2004, ch. 5.8.

53 L. G. Harrison, Trans. Faraday Soc., 1961, 57, 1191.

54 R. D. Shannon, Acta Crystallogr., Sect. A: Found. Crystallogr., 1976, 32, 751.

55 M. Cherry, M. S. Islam and C. R. A. Catlow, J. Solid State Chem., 1995, 118, 125.

56 M. S. Khan, M. S. Islam and D. R. Bates, J. Phys. Chem. B, 1998, 102, 3099.

57 M. Lerch, H. Boysen and T. Hansen, J. Phys. Chem. Solids, 2001, 62, 445.

58 M. Schie, A. Marchewka, T. Müller, R. A De Souza and R. Waser, J. Phys.: Condens. Matter, 2012, 24, 485002. 